\title{
13-year follow-up multidisciplinary management of replanted avulsed permanent incisor: Case report
}

Bharbara Marinho Barcellos ${ }^{1 \mathrm{a}}$, Giselle Daer Faria ${ }^{2 \mathrm{~b}}$, Josué Martos ${ }^{1 \mathrm{c}}$ iD, Letícia Kirst Post ${ }^{1 \mathrm{~d}}$ iD, Cristina Braga Xavier ${ }^{1 \mathrm{~d}}$ iD

\section{ABSTRACT}

Background: Avulsion of permanent teeth represents a high rate among all dental trauma injuries and their rapid management is very important for prognosis. The aim of this present study is to report the multidisciplinary treatment and 13-years follow-up of a case of the replantation of a permanent maxillary central incisor after dental avulsion.

Clinical presentation: A 8-year-old male patient presented avulsion of the upper right central incisor associated with uncomplicated crown fracture of the both permanent central incisors was treated with replantation of the avulsed tooth. Due to anterior open bite, severe crowding of teeth in the trauma region, and Angle's Class II profile, an orthodontic approach was performed. Long-term follow-up at 13-years after the trauma, and 7-years after the beginning of orthodontic treatment, the appliance was removed, and a permanent root canal filling of right maxillary central incisor was performed. An in-office tooth whitening using $35 \%$ hydrogen peroxide was executed.

Clinical Relevance: The treatment of choice for a dental avulsion is to replant the tooth as soon as the trauma has occurred for a better prognosis.

Conclusion: Clinical results after 13-years follow-up showed the stabilization of the resorption and allowed orthodontic movement maintained the patient's health over time after the trauma.
1. Universidade Federal de Pelotas, Brazil.

2. Private Practice Dentistry, Bazil.

a. DDS, Maxillofacial Surgery Resident, Federal University of Pelotas, Pelotas, Brazil.

b. DDS, MS, PhD, Private Practice Dentistry, Pelotas, Brazil.

c. Professor, Department of Semiology and Clinics, School of Dentistry, Federal University of Pelotas, Pelotas, Brazil.

d. Professor, Department of Oral and Maxillofacial Surgery, School of Dentistry, Federal University of Pelotas, Pelotas, Brazil.

Correspondence:

Josué Martos

josue.sul@ terra.com.br

KEYWORDS:

Tooth avulsions; Trauma; Permanent Dentition; Tooth reimplantation; Follow Up Care; Case Report. 


\section{INTRODUCTION}

Dentoalveolar trauma can occur due to accidents involving sports, violence and traffic. $^{1,2}$ The incidence of permanent tooth trauma is between $7 \%$ and $19 \%$ of all body injuries and mainly affects the anterior maxillary teeth. ${ }^{3}$

Permanent teeth avulsion represents $0.5 \%$ to $3 \%$ of all dental injuries, since it is the most severe injury, its rapid management is very important for a good prognosis. ${ }^{4-6}$ The treatment of choice for avulsion is the reimplantation of the teeth as soon as the trauma occurs, preferably before the maximum extra-alveolar time of 60 minutes. ${ }^{7}$ Reimplantation may be considered a good option for preserving avulsed teeth, although some of the replanted teeth are less likely to survive at long time and may even be lost or extracted at a later stage. Andreasen et al. reported a survival rate of about $55 \%$ for replanted mature teeth after 10 years. ${ }^{8}$

Furthermore, replanted teeth can suffer discoloration, which may occur at the time of injury or in subsequent years. ${ }^{8,9}$ The prevalence of patients that had some history of injuries before the beginning of orthodontic treatment of previous is around $10.8 \% .{ }^{10}$ Due to the considerable proportion of child patients with previous dental trauma before beginning orthodontic care, orthodontists need to pay attention to the implications of tooth movement on traumatized teeth, measuring the prognosis before initiating on treatment. ${ }^{11}$ The aim of the present study is to report the multidisciplinary treatment and follow-up of 13-years of the case of a replantation after dental avulsion of a permanent maxillary central incisor associated with orthodontic management.

\section{CLINICAL PRESENTATION}

\section{Patient information}

An 8-year old boy was referred to the emergency unit of a local hospital after a dental trauma that resulted in avulsion of the upper right permanent central incisor and subluxation of the left central incisor associated with uncomplicated crown fracture of the right and left maxillary central incisor. In anamnesis, the patient described that he had suffered a facial trauma in an accidental impact due to fall from height.

\section{Clinical findings, diagnostic assessment and therapeutic interventions}

The right permanent central incisor was stored in saline solution for 1 hour and 30 minutes and posteriorly replanted by gently re-inserting it into the tooth alveolus. A ligature splints made with steel wire and composite resin was used by the surgeon to stabilize the tooth and antibiotic therapy was prescribed for seven days. The patient's parents were informed about the procedures.

On clinical examination, 1-week after the incident, the right permanent central incisor had grade II mobility. The rigid ligature splint was replaced with a flexible one extending from canine-to-canine and the initial treatment consisted of endodontic approach and calcium hydroxide therapy of the right maxillary central incisor and composite resin restoration of the right and left maxillary central incisor (Figure $1)$.

\section{Figure 1: Radiographic evaluation}

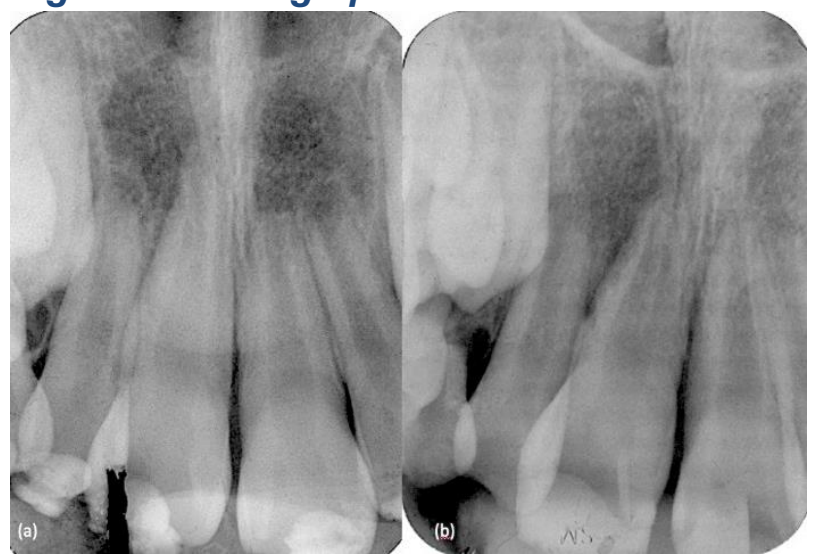

(a) Periapical radiography after reimplantation.

(b) Radiographic aspect after 1-month post-trauma.

After 1-month of the dental trauma and initial intervention, the root canal of the right permanent central incisor was approached to initiate theraphy with calcium hydroxide. At 3years, a radiographic examination presented signs of ankylosis of the 11 and post 1-year of this episode, the process of root resorption was 


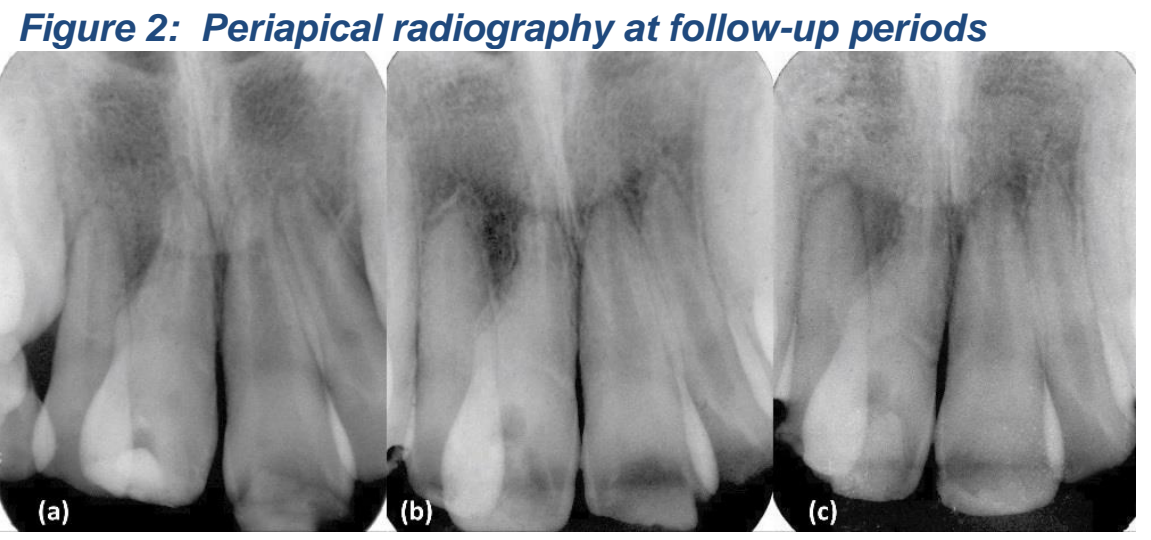

(a) 9-months (b) 35-months (c) 46-months.

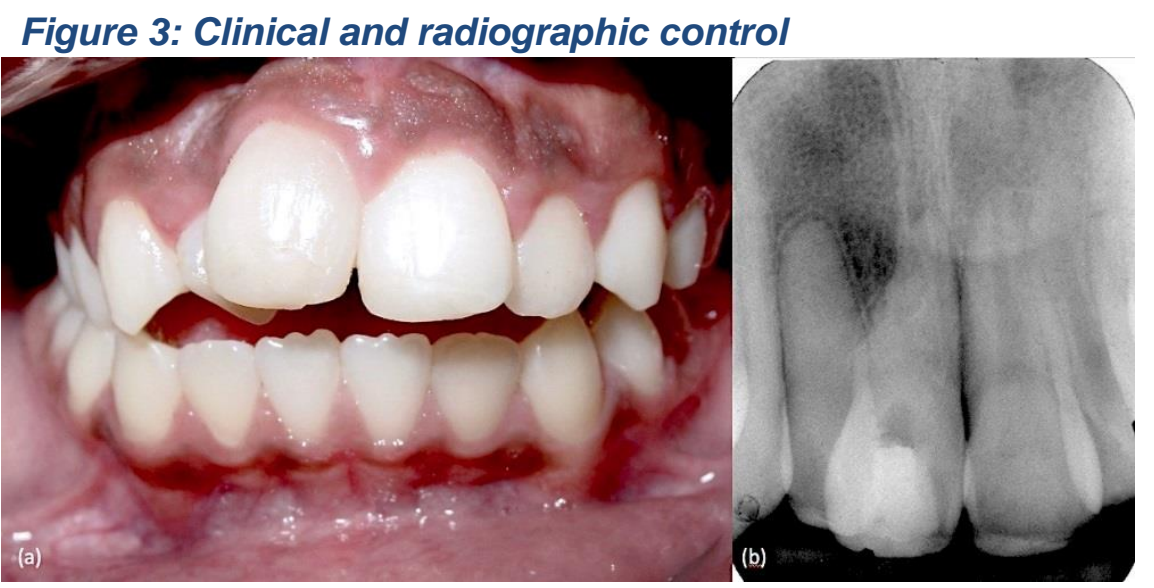

(a) Frontal view of the replanted maxillary central incisor at 4-years followup. (b) Periapical radiography at 5-years.

stabilized (Figures 2, 3).

Orthodontic evaluation identified anterior open bite, severe crowding of teeth 11,12 and 13 , specifically in the trauma region and Angle's Class II profile, division 1 and right subdivision. At this point an orthodontic approach was performed. The orthodontic planning consisted of extraction of tooth 14 and distalization of teeth 13 and 12 to allow traction of \#11 (Figure 4). Treatment was based on the force control of \#11, as this presented calcium hydroxide inside the root canal.

At 8-years after the trauma and 3-years after the beginning of orthodontic treatment, there was evidence root resorption progression of the right maxillary central incisor, so the orthodontic force was removed (Figure 5a). However, after 6-months of this episode, it was possible to reapply the force (Figure
$5 b)$.

Long-term follow-up at 12-years after the trauma, and 7-years after the beginning of orthodontic treatment, orthodontic appliance was removed, and a permanent root canal filling of right maxillary central incisor was performed. Even though it is not recommended by IADT to maintain calcium hydroxide for a long period of time, we consider it safer for orthodontic movement to maintain and thus prevent further root resorption. Subsequently, the patient underwent an in-office tooth whitening protocol using $35 \%$ hydrogen peroxide at right maxillary central incisor as a function of crown darkening (Figure 6).

\section{Long-term follow-up}

Clinical and radiographic follow-up after 13years of the dental trauma and replantation, 
teeth 11 and 12 show no clinical or radiographic signs of root resorption, healthy periodontium, and the mesial bone crest followed the extrusion of the element 11 (Figure 7). During this follow-up period, pulp calcification of tooth 12 was observed. The root canal seems to be totally calcified and was decided not to intervene surgically, because it is stable and without indications of periapical injury throughout the period of follow-up evaluation (Figures 3, 4, 5, 7).

\section{Figure 4: Orthodontic treatment}

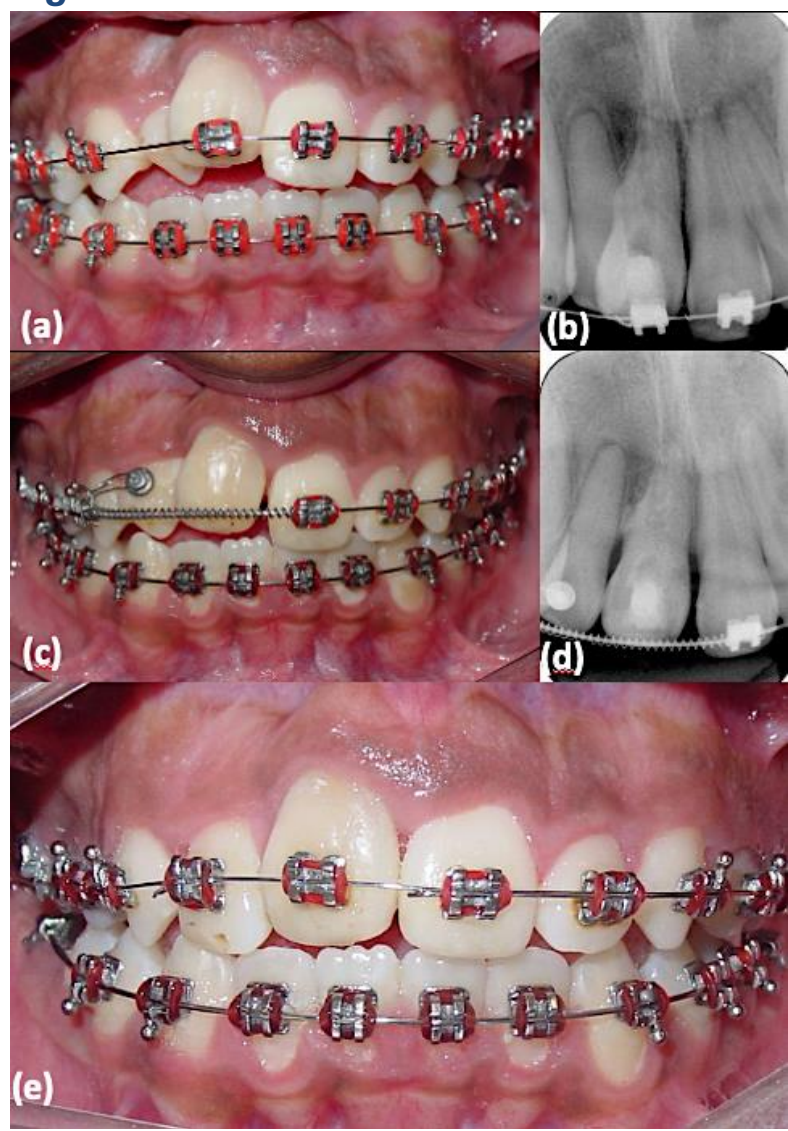

(a) Initial orthodontic treatment. (b) Periapical radiograph after installation of the orthodontic apparatus. (c) A 11-months of the initial orthodontic intervention. (d) Periapical radiograph at 11-months. (e) Orthodontic aspect at 15-months of the initial orthodontic treatment.

\section{CLINCAL RELEVANCE}

Dental trauma requires a correct diagnosis of the condition so that appropriate interventions and long-term follow-up can be done correctly. Some factors to note regarding the avulsed tooth are the location where the tooth was found, which storage medium was used
Figure 5: Radiographic evidence of orthodontic force

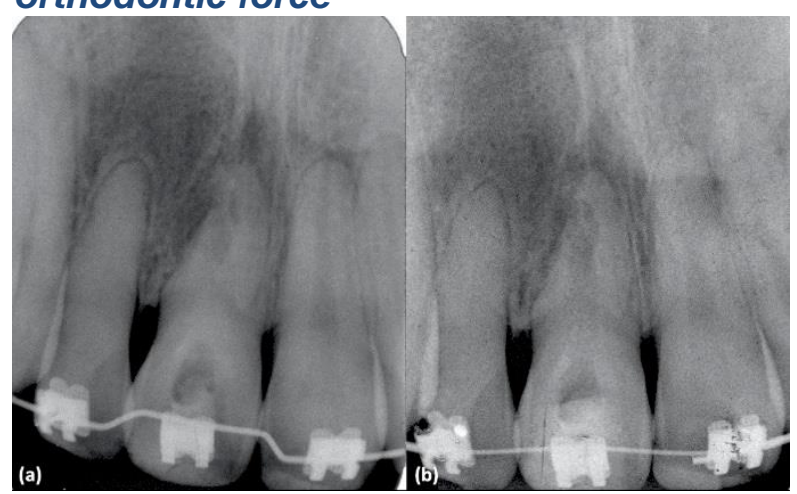

(a) Orthodontic force was removed after evidence of root resorption 6-years after the initial trauma. (b) Reapplication of the orthodontic force after 6months.

Figure 4: In-office tooth whitening

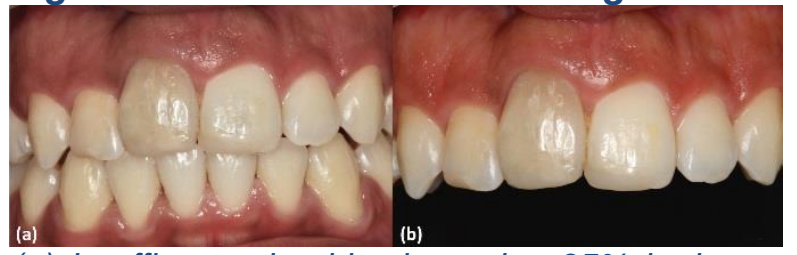

(a) In-office tooth whitening using 35\% hydrogen peroxide. (b) Approximate appearance.

Figure 4: Clinical and radiographic followup.

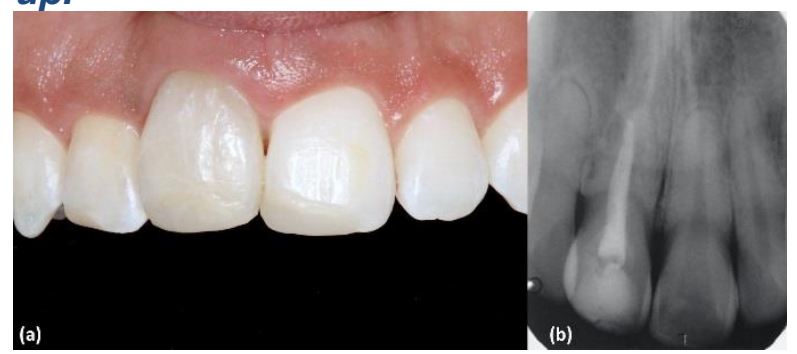

(a) Clinical appearance at the 13-years follow-up.

(b) Radiography at 13-years.

until replantation, whether it was sanitized prior to replantation and how much time the replantation was performed after the trauma. 8 Saline solution has physiological osmolarity and $\mathrm{pH}$, but does not contain essential ions and glucose, which are critical for cells and has therefore been suggested as an intermediate storage medium for up to 4-hours. ${ }^{12}$

In the present case, the decision to replace the rigid for flexible splint occurred because the last one allows physiological dental movement in order to reduce the risk of ankylosis or root resorption. ${ }^{13}$

The International Association of Dental 
Traumatology (IADT) guidelines prioritize that replanted teeth should be monitored for clinical and radiographic control after 4 weeks, 3 months, 6 months, 1 year and annually thereafter. ${ }^{14,15}$ Clinical and radiographic examination will provide information to determine the outcome. 8 In addition, if root canal treatment is indicated, the ideal time to start treatment is 7 to 10 days post-replantation. To maintain its $\mathrm{pH}$ at a bactericidal level and prevent root resorption, calcium hydroxide paste must be periodically renewed based on radiographic control of its radiopacity. ${ }^{16}$

In a 12-year systematic review of the literature, it was stated that most dental trauma injuries affect a single tooth, mostly involving the anterior teeth and particularly the upper incisors. ${ }^{17}$ Dento-alveolar trauma seems to increase the possibility of complications during orthodontic treatment. There is no consensus in the literature regarding the exact moment for the definitive root canal filling of traumatized teeth. Concomitantly, orthodontic treatment may be integrated into post-trauma treatment provided that planning and prognosis are carefully considered.

Although the reimplanted incisor showed radiographic signs of ankylosis at 3-years, the tooth had a positive extrusive movement with orthodontic force. The participation of bone tissue in this orthodontic context (when comparing the initial and final radiographs), allowed us to conjecture that something similar to an osteogenic distraction without ostectomy occurred.

Orthodontic movement in previously traumatized teeth is a problem in the orthodontist's routine. An interesting study found that traumatized teeth subjected to orthodontic intrusion have higher rates of pulpal necrosis than orthodontically treated non-traumatized teeth. ${ }^{18}$ Tooth movement in connection with endodontically treated teeth, already previously avulsed teeth, and partially avulsed teeth has been reported to give a higher frequency of root resorption, as in our case replacement resorption (ankylosis), than such movement of uninjured teeth. Although, there is little information in the literature about orthodontic treatment in traumatized teeth and no reported evidence of orthodontic forces applied to teeth containing only calcium hydroxide paste as root canal filling, we found that is possible to have success in these cases if the management is well conducted with a permanent clinical/radiographic follow-up.

\section{CONFLICT OF INTEREST:}

The authors declare that they have no conflicts of interest with respect to this article.

\section{REFERENCIAS:}

[1] Wright G, Bell A, McGlashan G, Vicent C, Welbury RR. Dentoalveolar in Glasgow: an audit of mechanism and injury. Dent Traumatol. 2007;23(4):226-31. DOI: 10.1111/j.1600-9657.2006.00430.x

[2] Koyuturk AE, Kusgoz A. Multiple dentoalveolar traumatic injury: a case report (3 years follow up). Dent Traumatol. 2008;24(4):e16-9. DOI: 10.1111/j.16009657.2008.00579.x

[3] Sheroan MM, Roberts MW. Management of a complex dentoalveolar trauma with multiple avulsions: a case report. Dent Traumatol. 2004,20(4):222-5. DOI: 10.1111/j.1600-9657.2004.00226.x.

[4] Andersson L, Andreasen JO, Day $P$, Heithersay G, Trope M, DiAngelis AJ, et al. International Association of Dental Traumatology guidelines for the management of traumatic dental injuries: 2 . Avulsion of permanent teeth. Dent Traumatol. 2012; 28(2): 88-96. DOI: 10.1111/j.1600-9657.2012.01125.x

[5] Glendor U, Halling A, Andersson L, EilertPetersson E. Incidence of traumatic tooth injuries in children and adolescents in the county of Västmanland, Sweden. Swed Dent J. 1996;20(1-2):15-28.

[6] Andreasen JO, Andreasen FM. Avulsions. In: Andreasen JO, Andreasen FM, Andersson L, editors. Textbook and color atlas of traumatic injuries to the teeth, $4 a$ ed. Oxford, UK: Wiley-Blackwell; 2007.44488.

[7] Andreasen JO, Jensen SS, Sae-Lim V. The role of antibiotics in preventing healing complications after traumatic dental injuries: a literature review. Endod Topics. 
2006; 14(1):80-92. DOI: 10.1111/j.16011546.2008.00231.x

[8] Andreasen JO, Borum MK, Jacobsen $\mathrm{HL}$, Andreasen FM. Replantation of 400 avulsed permanent incisors. 1. Diagnosis of healing complications. Endod Dent Traumatol. 1995;11(2): 51-8. DOI: 10.1111/j.1600-9657.1995.tb00461.x

[9] Heithersay GS. Life cycles of traumatized teeth: long-term observations from a cohort of dental trauma victims. Aust Dent J. 2016;61(1):120-7. DOI: 10.1111/adj.12403

[10] Bauss O, Röhling J, Schwestka-Polly R. Prevalence of traumatic injuries to the permanent incisors in candidates for orthodontic treatment. Dent Traumatol. 2004;20(2):61-6. DOI: 10.1111/j.16004469.2004.00230.x.

[11] Kindelan SA, Day PF, Kindelan JD, Spencer JR, Duggal MS. Dental Trauma: an overview of its influence on the management of orthodontic treatment. Part 1. J Orthod. 2008;35(2):68-78. DOI: 10.1179/146531207225022482

[12] Martins WD, Westphalen FH, Westphalen VP, Souza PH. Multiple dentoalveolar traumatic lesions: report of a case and proposition of dental polytrauma as new term. J Contemp Dent Pract 2004;5(4):139-47.

[13] Von Arx T, Filippi A, Lussi A. Comparison of a new dental Trauma Splint Device (TTS) with three commonly used splinting techniques. Dent Traumatol. 2001;17(6):266-74. DOI: 10.1034/j.1600-9657.2001.170605.x

[14] Olsburgh S, Jacoby T, Krejci I. Crown fractures in the permanent dentition: pulpal and restorative considerations. Dent Traumatol. 2002;18(3):103-15. DOI: 10.1034/j.1600-9657.2002.00004.x

[15] Flores MT, Andersson L, Andreasen JO, Bakland LK, Malmgren B, Barnett $F$, et. al. Guidelines for the management of traumatic dental injuries. II. Avulsion of permanent teeth. Dent Traumatol. 2007;23(3):130-6. DOI: 10.1111/j.16009657.2007.00605.x

[16] Andreasen JO, Jensen L, Christensen SSA. Relationship between calcium hydroxide $\mathrm{pH}$ levels in the root canals and periodontal healing after replantation of avulsed teeth. Endod Topics.
2008;14(1):93-101. DOI: 10.1111/j.16011546.2008.00227.x

[17] Glendor U. Epidemiology of traumatic dental injuries - a 12 year review of the literature. Dent Traumatol. 2008;24(6):603$11 . \quad$ DOI:

$10.1111 / \mathrm{j} .1600-$ 9657.2008.00696.x

[18] Bauss O, Freitag S, Röhling J, Rahman A. Influence of overjet and lip coverage on the prevalence and severity of incisor trauma. J Orofac Orthop. 2008;69(6):40210. DOI: $10.1007 / \mathrm{s} 00056-008-8805-1$

\section{HOW TO CITE THIS ARTICLE}

Marinho B, Daer G, Martos J, Kirst L, Braga C. 13-year follow-up multidisciplinary management of replanted avulsed permanent incisor: case report. Appli Sci Dent. 2021:1(1);32-7

DOI: 10.22370/asd.2021.1.1.2448

Applied Sciences in Dentistry, scientific journal of the Faculty of Dentistry of the University of Valparaíso, Open Access and Continuous Publication.

Original and unpublished works are accepted, including letters to the editor, brief communications, research articles, case reports and reviews.

Contact e-mail:

contacto.asdj@uv.cl

editor.asdj@uv.cl

Web site:

https://revistas.uv.cl/index.php/asid

Social media

Instagram @asd.journal

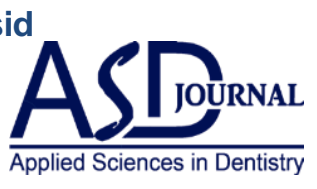

